\title{
Improving high school students' conceptual understanding of electricity and magnetism using scaffold analogy instructions
}

\author{
Aysheshim Mengistu ${ }^{1}$ a. *, Shimels Assefa ${ }^{1 \text { b., Desta Gebeyehu }}{ }^{1 \mathrm{c} .}$ \\ ${ }^{1}$ Addis Ababa University. NBH1, 4killo King George VI St, RU8002, Ethiopia.

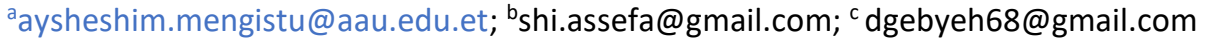 \\ * Corresponding Author.
}

Received: 16 November 2021; Revised: 12 December 2021; Accepted: 2 January 2022

\begin{abstract}
Simulated analogical teaching model has a novel contribution in enhancing students' learning. This study aims to analyze effect of simulated analogies scaffold by group discussion model in improving students' conceptual understanding of some selected contents of electricity and magnetism at high school level. The study involved 75 grade 10th students from two different high schools, namely Dagmawi Twodros and Fert high schools found in Debre Tabor Town, South Gondar, Amhara region, Ethiopia. A quasiexperimental method with pretest posttest design was used in the study. An adapted standardized test of electricity and magnetism conceptual understanding test (EMCUT) was used to collect data. The reliability of EMCUT was checked using KR-20 and found to be at about .81. After checking all necessary assumptions, an independent sample t-test was used to analyze the mean difference on students EMCUT scores between groups. From the result analysis, we found that experimental group who used simulated analogies scaffold by group discussion method in learning of electricity and magnetism showed a higher mean score of EMCUT than the control group. Thus, it can be concluded that the use of simulated analogies scaffold by group discussion model improved high school students' conceptual understanding of electricity and magnetism.

Keywords: Conceptual understanding; electricity and magnetism; simulated analogies.
\end{abstract}

How to Cite: Mengistu, A., Assefa, S., \& Gebeyehu, D. (2022). Improving high school students' conceptual understanding of electricity and magnetism using scaffold analogy instructions. Momentum: $\quad$ Physics $\quad$ Education Journal, 6(1), 29-38. https://doi.org/10.21067/mpej.v6i1.6223

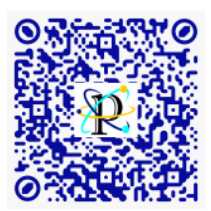

\section{Introduction}

Now a day's, human being endeavor to have a modern life style which would come as a result of the education system they had. Many countries in the glob have turned their view, attention and efforts on ensuring the quality of education delivered to citizens by all levels of school as it be lower school, secondary school and tertiary level schools. In due fact, nations have been made a number of reforms in the education for achieving a better success by attaining it within a bounded framework. One of the big issues for making reforms in education concerned by governments, academicians and others who involved in the education sector is improving students' academic performance in the field (Barnes et al., 2018). Science education has also its own contribution in improving and modernizing human life through the delivery of quality and scientific understandings in school learnings.

Physics is, one of the natural science fields, essential scientific discipline in science education where students should learn as designed by the curriculum used in the school setting. Physics has played its own role to build up students with multiple knowledge, skills and attitudes so as to understand nature and solve problems they face in their life. To achieve this broad goal, governments in any nation include an agenda in their curriculum on students must learn science subjects by integrat- 
ing each other and other subjects. To this end, students can use their understanding to solve problems they faced in their daily life and discover nature.

Efforts made in education reforms include a number of factors such as contextualizing text books, improving performance and proficiency of teachers, organizing schools with facilities and improving the teaching learning instruction (Benavot \& Köseleci, 2013; ESDP, 2002; Freeman, Marginson, \& Tytler, 2019). These documents and reports indicated that governments have also a great concern on improving the quality of instructional strategies used in schools by endeavoring it to enhancing learners' engagement, interaction and creativity. The reports were also showed that many activities were implemented using projects facilitated in making a paradigm shift to link the instructional strategies used for students learning become more of student-centered and encourage teachers to consider involving students as a key actors for learning.

A number of studies and reports have been done and documented that students' academic performance were declining typically in sciences fields and mathematics (Council, 2013; Mullis \& Martin, 2017). In addition, many research findings claimed that students' academic achievement was reduced due to many factors. The factors that hindered students' academic performance were identified and reported as social economic status, daily study hours and accommodation trends, poor teacher's qualification, large class size, poor classroom teaching and learning environment in the classroom, and inappropriate use of teaching methods (Maganga, 2016).

Good conceptual understanding of physics contents at secondary school level is a foundation for students to proceed for further learning. But studies reported that most students still failed to understand the concepts in science in general and in physics in particular (Alonzo \& Gotwals, 2012; Amin et.al., 2014; Babajide et al., 2018). Research findings also indicated that students had misconceptions in many electricity and magnetism contents (Dega et al., 2013; Guisasola et al., 2004; Mekonnen, 2014). These studies showed that most students had difficulties and misconceptions on the concepts of current, resistance, potential difference, sources of electrical energy, electric field, and magnetic fields.

Ahmady et al. (2020) indicated that misconceptions and difficulties of understanding in science are mainly arise from the teaching methods used by teachers in the science classroom. Ahmady et al. (2020) also claimed that the poor teaching methods used by teachers was directly contributing for students low academic performance in science subjects and the study also showed that the teaching methods used by science subject teachers failed to inculcate students prior knowledge and experience rather it focuses on knowledge retention that actually makes concepts difficult to understand by learners.

Activities made by governments in their education agenda had been also focused on providing appropriate physics instruction in the classroom but still students achieved a poor mark in physics in all around the world (Awodun et al., 2014). Similar reports were presented on students poor performance in physics typically concerned with low mark scores in national examination by Ethiopian high school students (Minstry of Education, 2010; MoE, 2017; NLA, 2013; Tadesse, Manathunga, \& Gillies, 2018).

Multiple studies reported that different types of physics classroom instructions were suggested and employed to improve the situation (Mekonnen, 2014; Noh et al., 2016; Omar, 2017; Putri, 2017). But, still the findings of these studies reported that students typically in middle schools and high schools did not show a significant improvement in their physics conceptual understanding, achievement and motivation towards physics learning even if the focus of this study was on conceptual understanding in the subject. The findings of the studies also claimed that the teaching methods used by physics teachers in the classroom were not in apposition to include students' prior experience and knowledge to boost learning of new and abstract contents and concepts in physics to the desired level.

The above mentioned studies claimed that the use of an effective classroom instruction is the research area to be further investigated and coming up with a better instruction to help students in their physics learning at any school level. Even though there are many factors that affect students' physics concept understanding, it is essential to have an innovative learning method that encapsu- 
lates student's prior knowledge, prior experience and implemented by physics teachers at high school level in order to enhance students' conceptual understanding in physics in general, electricity and magnetism in particular.

Learning is increased when learners attempt to build explanatory answers for questions arose during group discussion and interaction for the learning of new information. This can be achieved due to the explanations given by students to use what they already now to learn the unfamiliar one and linking the similarities between the old or familiar knowledge with the unfamiliar content to be learned. Therefore, from the essence of using learners' experience and prior knowledge, this study was selected an alternative physics classroom teaching instruction called simulated analogical reasoning scaffold by group discussion method to enhance students' conceptual understanding of the contents of electricity and magnetism at grade 10 th level.

Analogical reasoning is common and taken as a human cognition. Everyone has used analogies to explain and elaborate new information and phenomenon to others. Therefore, analogical reasoning was used in physics classroom teachings, but still the problem of students' difficulties of conceptual understanding and low achievement did not alter as the optimal level. In this study, we used analogy using a simulation plat form and blending it with group discussion in classroom physics teaching. The theory of social constructivism guided the implementation of the scaffold analogical reasoning method for the experimental group learning of the contents of electricity and magnetism. During the presentation of contents using the designed instructional model, students were engaged in the process to develop their cognitive abilities through group interaction with their group members and the teacher. The teacher displays the analogy first and then students were participating and engaged in connecting the base domain with the target domain by making a structural mapping. Students were interacting with each other and with the teacher to make a clear mapping by transforming similarities and avoiding the unmapped domains from the analogy and made generalizations about the new concept to be learned with building a meaningful knowledge structures. So, in this study we were hypothesized and tested whether the scaffold analogical reasoning can fit with the Ethiopian physics education system that needs students to understand concepts included in the physics text book or not.

Many studies indicated that analogical reasoning method had a positive impact on students' physics learning (Brown \& Salter, 2010; Cinyere \& Madu, 2014; Cruz-Hastenreiter, 2015; Lambert, 2011; Lancor, 2014). But, these studies still claimed that students have difficulties on conceptual understanding, and they usually failed to identify the point where the analogy breaks, and they were unable to see the analogy itself, simply they remembered the analogy instead of the concepts being learned. Therefore, this study went to scaffold analogical reasoning instruction by a means of simulation and group discussion to tackle students' physics learning problem. This study was aimed to investigate the effect of simulated analogical reasoning scaffold by group discussion on high school students' conceptual understanding of electricity and magnetism at grade 10th level in Ethiopian context. To achieve this research objective, it was hypothesized that there was no statistically mean score difference on students' conceptual understanding test between groups who were treated with simulated analogical reasoning scaffold by group discussion over comparison groups who were treated the same contents of electricity and magnetism using conventional method.

\section{Methods}

A non-equivalent quasi-experimental method with a pretest- posttest design was used for this study. Grade 10th students found in Tewodros and Fert high schools found in South Gondar Zone, Amhara Region, Ethiopia were selected randomly as samples of the study. Students at this grade level were selected as a sample for this study due to their age 14 to 16 years old believed to have abilities to use logic, link prior knowledge to the new contents to be learned and the contents of electricity and magnetism suitable to use analogies were found in depth manner at this grade level. The syllabus for grade 10 physics prepared by the Ethiopian ministry of education showed that students were expected to master the concepts included under the grade 10th physics text book and 
good understanding at this level believed to be the foundations for further learning. One section from each school were selected using a random sampling technique. Grade 10th students from one section in Tewodros high school was selected as an experimental group and one section from Fert high school was selected as a control group. The Experimental group (EG) was treated with simulated analogical reasoning supported by group discussion whereas the control group were treated by conventional method for the learning of selected contents of electricity and magnetism.

Table 1. Groups Intervention Procedures.

\begin{tabular}{llll}
\hline Group & Pre-Test & Treatment & Post-Test \\
\hline Experimental Group (EG) & $\mathrm{O}_{1}$ & $\mathrm{X}$ & $\mathrm{O}_{2}$ \\
Control Group (CG) & $\mathrm{O}_{1}$ & - & $\mathrm{O}_{2}$ \\
\hline
\end{tabular}

$\mathrm{O}_{1}$ : Pre-test used to see students' conceptual understanding level before intervention.

X: Simulated Analogies Scaffold by Group Discussion Method Used by EG only.

$\mathrm{O}_{2}$ : Post-test used to see students' conceptual understanding level after intervention.

Electricity and magnetism conceptual understanding test (EMCUT) of 14 multiple choice items adapted from different standardized tests were used to collect data. Pre-test was administered before the start of intervention for both experimental and control groups. After giving a training about the instructional material for implementing simulated analogical reasoning scaffold with group discussion to one physics teacher participated in the teaching of experimental group, the intervention was made for a couple of 6 weeks. The simulated analogies were displayed by the physics teacher through the use of plasma television found in the physics classroom. The researcher had made a support for the physics teacher both in planning and implementation of the designed simulated analogies in the physics lesson. Then after the end of intervention, a post test of electricity and magnetism conceptual understanding test (Post-EMCUT) as was administered for both experimental and control groups.

Once both the pre-test and post-test data of conceptual understanding of electricity and magnetism were collected, coded and entered into SPSS version 26, assumptions of test statistics were checked to evaluate a statistically significant mean difference in the pre-test and post-test scores between the two groups was exist or not. By checking the assumptions of normality and homogeneity of data, as we found that no assumption was not markedly violated, so that an independent sample t-test was used to evaluate the mean difference between the two groups.

\section{Results and Discussion}

In this study, the list of simulated analogies used were simulated water flow from a reservoir that falls on a wood cut machines, simulated earth's gravitational field, electric field and associated electric force between point charges simulation and text forms include gravitational field strength, Newton's law of universal gravitation, formulas of equivalent capacitance for series and parallel combinations which were prepared in the form of power points and simulation. So, the teacher display these analogies during the lesson in combination with the target concepts to be learned and then students were going to made mappings from the simulated analogies towards the new content to be learned. During mapping, students were engaged in group interaction and discuss about the explanations they brought from about the anlogy to transfer attributes. Before the start of implementing the instruction and after covering learning of the selected contents of electricity and magnetism at grade 10th level by EG, Electricity and Magnetism Conceptual Understanding Test (EMCUT) was administered as pre-test before treatment and post-test after treatment for EG and CG. The result showed that both groups showed a better conceptual understanding score than their pre-test score as shown in the Figure 1. 


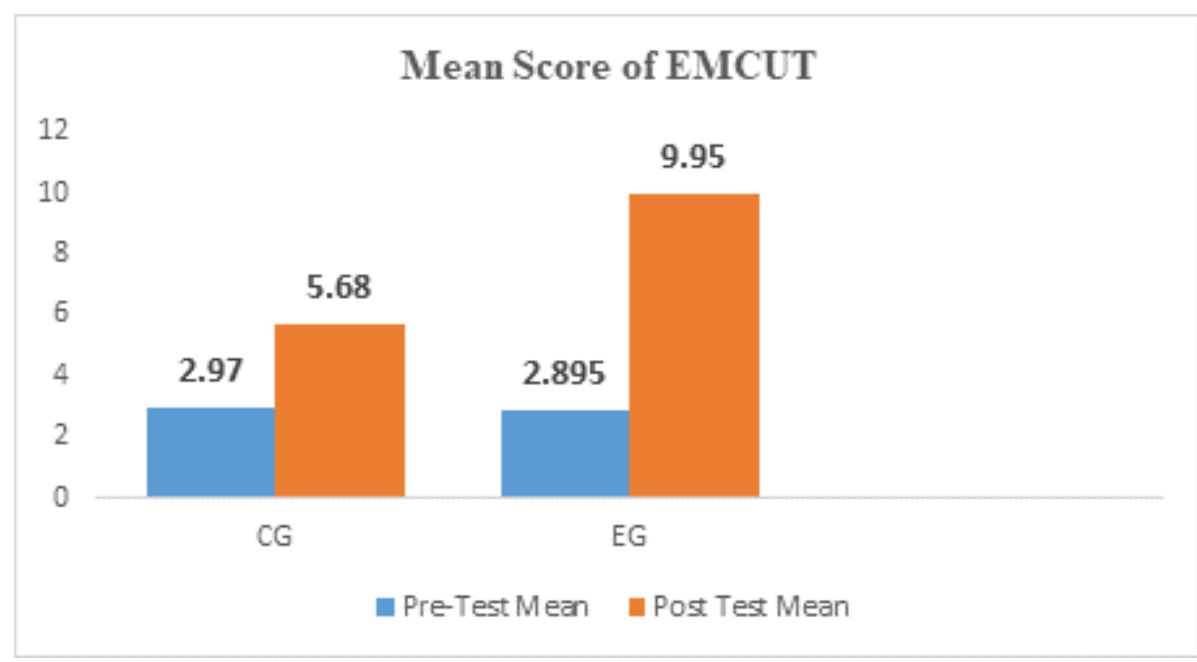

Figure 1. Students' Conceptual understanding Pre and post test scores of groups.

There was a mean difference on Pre-test score of conceptual understanding test between the experimental and control groups. Here, an independent sample t-test was run to evaluate whether the pre-test mean score of electricity and magnetism was statistically significant or not. The result analysis was presented in Table 2.

Table 2. Descriptive Statistics of Pre-EMCUT scores by Groups.

\begin{tabular}{llllllllll}
\hline & \multicolumn{4}{c}{ Pre-EMPUT Score } & \multicolumn{4}{c}{ Post-EMPUT Score } \\
\hline & $\mathrm{N}$ & $\mathrm{M}$ & $\mathrm{SD}$ & Skew & Kurtosis & $\mathrm{M}$ & SD & Skew & Kurtosis \\
\hline EG & 37 & 2.90 & 1.25 & .55 & .49 & 9.95 & 2.28 & -1.42 & -.32 \\
CG & 38 & 2.97 & 1.40 & -.040 & -.72 & 5.68 & 2.11 & -.089 & 1.61 \\
\hline
\end{tabular}

The electricity and magnetism conceptual understanding pre-test data distribution on Table 2 were sufficiently normal for conducting an independent sample t-test with skewness $<| \pm 2.0|$ and kurtosis $<| \pm 7.0|$ (Schmider, Ziegler, Danay, Beyer, \& Bühner, 2010). In addition, the assumption of homogeneity of variance was tested and satisfied using Levene's $F$ test, $F(73)=1.01, p=.32$ shown on table 3 below. It was hypothesized that there was no a statistically significant mean difference on Pre-EMCUT score between the experimental group $(M=2.97, S D=1.40)$ and control group $(M=2.89$, $S D=1.25)$. To test this null hypothesis, an independent sample $t$-test was used and the results were reported at Table 3.

Table 3. Independent sample t-test of Pre-EMCUT scores between Groups.

\begin{tabular}{lllllllllllll}
\hline & \multicolumn{11}{c}{ Independent sample Test } \\
\hline & Levene's Test & \multicolumn{1}{c}{ Test of Equality of Means } & \multicolumn{3}{c}{$\mathrm{Cl} 95 \%$} \\
\hline Pre -EMCUT & Equal variance assumed & $\mathrm{F}$ & sig & $\mathrm{t}$ & $\mathrm{df}$ & sig & $\mathrm{MD}$ & $\mathrm{SE}$ & Lower & Upper \\
& & 1.01 & .32 & -.26 & 73 & .79 & -.078 & .31 & -.69 & .53 & .53 \\
\hline
\end{tabular}

The independent sample t-test on Table 3 showed that there was no a statistically significant mean difference on Pre-EMCUT score between experimental and control groups, $t(73)=-.26, p=.79$. This indicated that we were not able to reject the null hypothesis. The result analysis revealed that both the experimental and control group high school students were found on the same level of electricity and magnetism conceptual understanding.

After an intervention had made for the experimental group using simulated analogical reasoning scaffold by group discussion in learning the concepts of electricity and magnetism and control group was treated by any conventional method, a Post-EMCUT was administered. The assumption of normality was not violated as skewness $<| \pm 2.0|$ and Kurtosis $<| \pm 7.0|$ (Schmider et al., 2010). Therefore, Post-EMCUT score data was approximately normally distributed as shown on Table 2 above. Besides the assumption of homogeneity of variance was tested and satisfied via Levene's Ftest, $\mathrm{F}=.633, \mathrm{p}=.429$ as indicated in Table 4. To examine the difference on Post-EMCUT between 
groups, it was hypothesized that there was no statistically significant difference on the mean PostEMCUT score between experimental and control group. To test this null hypothesis, an independent sample t-test was used and the results were presented at Table 4.

Table 4. Independent sample t-test of Post-EMCUT scores between Groups.

\begin{tabular}{lllllllllllll}
\hline \multicolumn{11}{c}{ Independent sample Test } \\
\hline & Levene's Test & \multicolumn{1}{c}{ Test of Equality of Means } & \multicolumn{3}{c}{$\mathrm{Cl} 95 \%$} \\
\hline Post -EMCUT & Equal variance assumed & $\mathrm{F}$ & sig & $\mathrm{t}$ & $\mathrm{df}$ & sig & $\mathrm{MD}$ & $\mathrm{SE}$ & Lower & Upper \\
& & .633 & .429 & -8.40 & 73 & .000 & -4.26 & .507 & -5.27 & -3.25 \\
\hline
\end{tabular}

The independent sample t-test was performed to compare the mean score difference on PostEMCUT between experimental and control groups. As predicted on Table 4, the experimental groups scored a statistically significant larger mean $(M=9.95, S D=2.28, N=37)$ than the control group ( $M$ $=5.68, \mathrm{SD}=2.11, \mathrm{~N}=38), \mathrm{t}(73)=-8.40, \mathrm{p}<.001$, two tailed. So that we reject the designed null hypothesis. That is the experimental group showed a statistically significantly larger mean in PostEMCUT than the control group. Cohen's d was estimated at 1.94, which is much larger effect based on Cohen (1992) guideline. The mean difference of the test score with the $95 \%$ confidence interval around the difference between group means was relatively precise $(-5.27$ to -3.25$)$. Therefore, the result analysis asserted that the change in mean for conceptual understanding of electricity and magnetism achieved because of the instructional teaching method used by the experimental groups.

The mean scores of Pre-EMCUT scores for CG and EG were 2.97, 2.89 and their Post-EMCUT mean scores were 5.68 and 9.95 as shown in the figure 2 below. The two groups showed a better mean score change after treatment. But to identify which learning method help groups to achieve a larger mean, normalized learning gain $\langle g\rangle$ was calculated using the formula:

$\langle g\rangle=\frac{(\% \text { Post }-\% \text { Pre })}{(100-\% \text { Pre })}$

The normalized learning gain was found to be .25 for CG who were treated with a conventional method and .63 for EG who were treated with simulated analogical reasoning scaffold by group discussion method in their learning of the concepts of electricity and magnetism respectively.

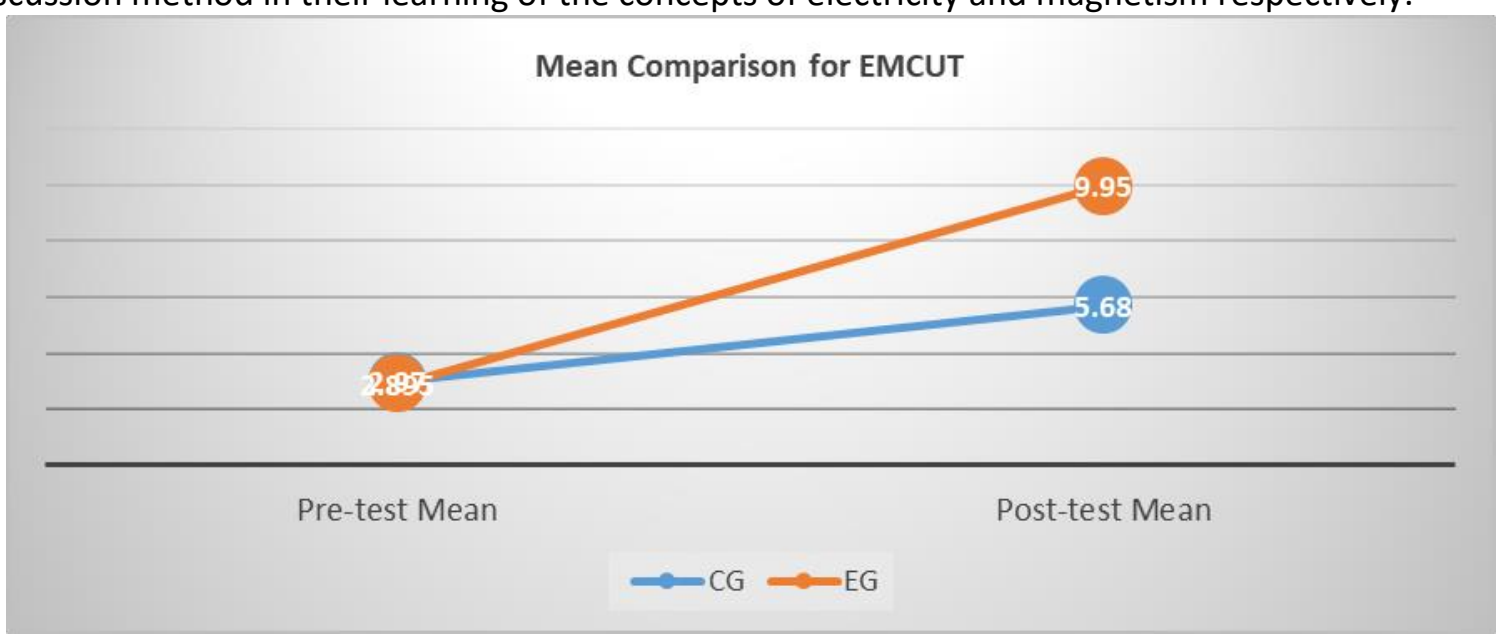

Figure 2. Mean Comparison of Pre-test and Post -test scores of ENCUT by EG and CG.

The normalized learning gain for CG .25 was low and for EG .63 was medium (Hake, 1998). From the mean normalized learning gain result analysis, it is possible to say that using simulated analogical reasoning scaffold by group discussion help to enhance students' conceptual understanding of electricity and magnetism than conventional method of teaching.

The result of of this study indicated that simulated analogy scaffold by group discussion method enhanced high school students' electricity and magnetism contents conceptual understanding. Many researches related to analogical reasoning instruction on students' conceptual understand- 
ing in physics had come up with both positive and negative effects. In this study, we hypothesized that high school students who were used scaffold analogical reasoning method showed better conceptual understanding of different contents of electricity and magnetism than students who were used conventionally designed instruction. The result of test analysis showed that simulated analogies scaffold by group discussion method help students to had better conceptual understanding of contents of electricity and magnetism than control groups. This result is consistent with other previous research findings in that analogical reasoning method can facilitate students' concept learning (Gilbert \& Justi, 2016; Hesti et al., 2017; Holyoak, 2012; Kola, 2017; Lancor, 2014).

The finding of this study revealed that students' conceptual understanding of some selected contents of electricity and magnetism such as the concept of charge, coulomb's force, electric field and its strength from a point charge, electric potential and electric potential energy, current, voltage, resistance, combination of resistors, electromotive force, magnetic field and the associated forces include in high school physics enhanced when simulated analogies were used in support of group discussion method. The result of this finding was in accordance with the study carried out on the use of analogies as it helps to increase learners mental process (Jonane, 2015; Zacks \& Friedman, 2020). The simulated analogical reasoning scaffold by group discussion method help students to structure and integrate new information with past experiences so that they can retrieve from memory so as to link with other concepts be learnt in another context. So, the simulated analogies scaffold by group discussion implemented in this study help learners to encode knowledge in the form of representations of abstract concepts in electricity and magnetism and construct a certain mental models. The findings of this study indicate that the simulated analogies scaffold by group discussion method enhances students to construct context free structural representations of the abstract concepts of electricity and magnetism stated in the physics text book.

Many research findings showed also that when analogies were supported by either other instructional strategy of platform creating a good environment for students to visualize the anlogy, students abilities of understanding abstract contents increased (Ugur et al., 2012; Wang et al., 2016; Zipke et al., 2019) which supported the finding of this study as the mean score of students conceptual understanding after treated with simulated analogies used for linking the analogue with the new target concept to be learned and make that link by forming a structural mapping through group interaction with a significant amount.

Some research findings indicated that analogies by their very nature facilitates conceptual understanding (Didiş, 2015; Gilbert \& Justi, 2016; Haglund, 2013). Iloputaife (2016) and Star and Stylianides (2013) were revealed analogy based instructions were effective for conceptual change and later conceptual understanding appeared. Still there were other research parties claimed that analogical reasoning instruction facilitate conceptual understanding and problem solving rather than executing conceptual change first (Davies, 2014). This study finding supported the first and third research finding categories. Through the process of implementation of the designed scaffold analogical reasoning instruction we had found that using analogy modeled instruction be effective what matters was ensuring the analogy be familiar to learners since analogues were a human cognition and common to explain something new without any planned activities, and creating an environment in which learners can see the analogy in a visible manner and link to the abstract concept to be learned and facilitating students engagement with group discussion or other type of mechanism so as to make meanings in collaboration with others.

\section{Conclusion}

The presented study showed that simulated analogies would affect students' conceptual understanding of contents of electricity and magnetism when it is scaffold by group discussion method. The great efforts made in this study can contribute an information to the physics education research community, physics educators and teachers about the use of analogies by scaffolding it with technology and other active learning method to adhere a better students' conceptual understanding in their learning. This study has indicated that when simulated analogies scaffold by group discussion 
method used systematically, students' conceptual understanding of different contents of electricity and magnetism improved more. Therefore, other science subject teachers can also use simulated analogies scaffold by group discussion method in their classroom teaching so as to improve students understanding.

\section{Acknowledgment}

This research work was successful with a great effort of my advisors Dr Shimelis Assefa and Dr Desta Gebeyhu who had contributed their relevant comments and advising me. My gratitude was also goes to my colleagues Zemenu Mihret, PhD candidate and Kassahun Dejene, PhD candidate who had helped me in thorough readings of the manuscript.

\section{References}

Ahmadi, G. A., Saberi, M., \& Ahmadi, F. (2020). The effect of group discussion teaching on students' reasoning ability in solving physics problems. https://dx.doi.org/10.22061/tej.2020.5614.2247

Alonzo, A. C., \& Gotwals, A. W. (2012). Learning progressions in science: Current challenges and future directions. https://brill.com/downloadpdf/book/edcoll/9789460918247/BP000020.pdf

Amin, T. G., Smith, C. L., \& Wiser, M. (2014). Student conceptions and conceptual change: Three overlapping phases of research Handbook of Research on Science Education, Volume II (pp. 7195): Routledge.

Awodun, A. O., Oni, S. A., \& Aladejana, A. L. (2014). Students' variables as predictor of secondary school students' performance in physics. Int. J. Sci. Res, 4, 541-545. http://www.ijsrp.org/research-paper-0914/ijsrp-p3375.pdf

Babajide, V., Adeyemo, S., \& Ogunleye, A. (2018). Quality and relevance of physics education in Nigeria: Foremost educational services limited, Lagos. https://ir.unilag.edu.ng/handle/123456789/9171

Barnes, A. E., Zuilkowski, S. S., Mekonnen, D., \& Ramos-Mattoussi, F. (2018). Improving teacher training in Ethiopia: Shifting the content and approach of pre-service teacher education. Teaching and Teacher Education, 70, 1-11. http://dx.doi.org/10.1016/j.tate.2017.11.004

Benavot, Aaron, Köseleci, \& Nihan. (2015). Seeking quality in education: the growth of national learning assessments, 1990-2013; Background paper prepared for the Education for all global monitoring report 2015, Education for All 2000-2015: achievements and challenges; 2015.

Brown, S., \& Salter, S. (2010). Analogies in science and science teaching. American Journal of Physiology Advances in Physiology Education, 34(4), 167169.https://doi.org/10.1152/advan.00022.2010

Cinyere, N., \& Madu, B. (2014). Effect of analogy teaching approach on students' conceptual change in physics. Greener Journal of Educational Research,4(4),119-125. http://dx.doi.org/10.15580/GJER.2014.4.032414160

Cohen, J. (1992). A power primer. Psychological Bulletin, 112(1), 155. https://psycnet.apa.org/doi/10.1037/0033-2909.112.1.155

Council, N. R. (2013). Adapting to a changing world: Challenges and opportunities in undergraduate physics education: National Academies Press.https://doi.org/10.17226/18312

Cruz-Hastenreiter, R. (2015). Analogies in high school classes on quantum physics. Procedia - Social and Behavioral Sciences, 167, 38-43. https://doi.org/10.1016/j.sbspro.2014.12.639

Davies, K. (2014). Teaching by analogy: Gravity and electrostatics: The University of Texas at Dallas.

Dega, B. G., Kriek, J., \& Mogese, T. F. (2013). Students' conceptual change in electricity and magnetism using simulations: A comparison of cognitive perturbation and cognitive conflict. Journal of Research in Science Teaching, 50(6), 677-698. https://doi.org/10.1002/tea.21096 
Didiş, N. (2015). The analysis of analogy use in the teaching of introductory quantum theory. Chemistry Education Research and Practice,16(2),355-376. https://doi.org/10.1039/c5rp00011d

ESDP, I. (2002). Education sector development program IV. Education Sector Development Program IV https://planipolis.iiep.unesco.org/upload/Ethiopia/Ethiopia_ESDP_IV.pdf

(2010/2011-2014/2015).

Freeman, B., Marginson, S., \& Tytler, R. (2019). An international view of STEM education STEM Education 2.0 (pp. 350-363): Brill Sense.https://doi.org/10.1163/9789004405400_019

Gilbert, J. K., \& Justi, R. (2016). Analogies in modelling-based teaching and learning Modelling-based teaching in science education (pp. 149-169): Springer. https://doi.org/10.1007/978-3-31929039-3_8

Guisasola, J., Almudi, J. M., \& Zubimendi, J. L. (2004). Difficulties in learning the introductory magnetic field theory in the first years of university. Science Education, 88(3), 443-464. http://dx.doi.org/10.1002/sce.10119

Haglund, J. (2013). Collaborative and self-generated analogies in science education. Studies in science Education, 49(1), 35-68. https://doi.org/10.1080/03057267.2013.801119

Hake, R. R. (1998). Interactive-engagement versus traditional methods: A six-thousand-student survey of mechanics test data for introductory physics courses. American Journal of Physics, 66(1), 64-74. https://doi.org/10.1119/1.18809

Hesti, R., Maknun, J., \& Feranie, S. (2017). Text based analogy in overcoming student misconception on simple electricity circuit material. Journal of Physics: Conference Series, 895(1). https://doi.org/10.1088/1742-6596/895/1/012146

Holyoak, K. J. (2012). Analogy and relational reasoning. https://www.researchgate.net/publication/285940144_Analogy_and_Relational_Reasoning

lloputaife, E. C. (2016). Effects of analogy and conceptual-change instructional models on physics achievement of secondary school students. University of Nigeria

Jonane, L. (2015). Using analogies in teaching physics: A study on latvian teachers' views and experience. In Journal of Teacher Education for Sustainability (Vol. 17, Issue 2, pp. 53-73). De Gruyter Open Ltd. https://doi.org/10.1515/jtes-2015-0011

Kola, A. J. (2017). Investigating the conceptual understanding of physics through an interactive lecture-engagement. Cumhuriyet International Journal of Education, 6(1), 82. http://cije.cumhuriyet.edu.tr/en/pub/issue/29856/321440

Lambert, K. (2011). The uses of analogy: James Clerk Maxwell's "On Faraday's lines of force" and early Victorian analogical argument. In British Journal for the History of Science (Vol. 44, Issue 1, pp. 61-88). https://doi.org/10.1017/S0007087410000439

Lancor, R. A. (2014). Using student-generated analogies to investigate conceptions of energy: A multidisciplinary study. International Journal of Science Education, 36(1), 1-23. https://doi.org/10.1080/09500693.2012.714512

Maganga, J. H. (2016). Factors affecting students' academic performance: A case of public secondary schools in Ilala District, Dares Salaam. The Open University of Tanzania.

Mekonnen, S. (2014). Problems challenging the academic performance of physics students in higher governmental institutions in the case of Arbaminch, Wolayita Sodo, Hawassa and Dilla Universities. Natural science, 2014. http://dx.doi.org/10.4236/ns.2014.65037

Minstry of Education, M. (2010). Education sector development program IV (ESDP IV). https://planipolis.iiep.unesco.org/upload/Ethiopia/Ethiopia_ESDP_IV.pdf

MoE, M. O. E. (2017). Asessment of planning and programming of GEQIP Implimentations by Implimenting

Entities., Unpublished. 
https://documents.worldbank.org/curated/en/128401513911659858/pdf/ETHIOPIA-EDUCPAD-11302017.pdf

Mullis, I. V., \& Martin, M. O. (2017). TIMSS 2019 assessment frameworks: ERIC.

NLA, N. L. A. (2013). Report on Ethiopian grade10 and 12 National examination Result Assessment, Unpublished.

http://documents1.worldbank.org/curated/en/141401597014133031/pdf/Ethiopia-SecondGeneral-Education-Quality-Improvement-Project.pdf

Noh, N. M., Wong, K.-T., Yeop, M. A., \& Abdullah, N. (2016). Blended learning: its implementation and promote continuing e-learning environment among student-teachers. International Journal of ADVANCED AND APPLIED SCIENCES,3(11),12-15. https://doi.org/10.21833/ijaas.2016.11.003

Omar, H. (2017). Determinants of students enrolment in physics in Kenya certificate of secondary education in public secondary schools in Kenya: a Case of Wajir County. University of Nairobi. http://hdl.handle.net/11295/101425

Putri, E. (2017). Improving the physics education achievement with mapping concept. Asian Journal of Natural \& Applied Sciences Vol, 6, 4. http://www.ajsc.leenaluna.co.jp/AJSCPDFs/Vol.6(4)/AJSC2017(6.4-15).pdf

Schmider, E., Ziegler, M., Danay, E., Beyer, L., \& Bühner, M. (2010). Is it really robust? Methodology. https://psycnet.apa.org/doi/10.1027/1614-2241/a000016

Star, J. R., \& Stylianides, G. J. (2013). Procedural and conceptual knowledge: Exploring the gap between knowledge type and knowledge quality. Canadian Journal of Science, Mathematics and Technology Education, 13(2), 169-181. https://doi.org/10.1080/14926156.2013.784828.

Tadesse, T., Manathunga, C. E., \& Gillies, R. M. (2018). Making sense of quality teaching and learning in higher education in Making sense of quality teaching and learning in higher education in Ethiopia: Unfolding existing realities for future promises Ethiopia: Unfolding existing realities for future promises. Journal of University Teaching \& Learning Practice, 15. https://doi.org/10.14453/jutlp.v15i1.4

Ugur, G., Dilber, R., Senpolat, Y., \& Duzgun, B. (2012). The effects of analogy on students' understanding of direct current circuits and attitudes towards physics lessons. In International Journal of Environmental \& Science Education (Vol. 3). http://www.akademikplus.com/eujer/index.html

Wang, L., Zhang, J., Jiang, B., \& Zhao, H. (2016). Application of analogy method in the electromagnetism teaching in college physics. https://dx.doi.org/10.2991/mcei-16.2016.221

Zacks, O., \& Friedman, J. (2020). Analogies can speed up the motor learning process. Scientific Reports, 10(1). https://doi.org/10.1038/s41598-020-63999-1

Zipke, M., Ingle, J. C., \& Moorehead, T. (2019). The effects of modeling the use of technology with pre-service teachers. Computers in the Schools, 36(3),205-221. https://doi.org/10.1080/07380569.2019.1640038 